\title{
$\mathrm{H}$ \\ - овая комбинированная наружная терапия торпидных форм розацеа
}

Смирнова Е. А. ${ }^{*}$, Олисова О. Ю., Кочергин Н. Г.

Первый Московский государственный медицинский университет им. И. М. Сеченова (Сеченовский университет) Министерства здравоохранения Российской Федерации

119991, Российская Федерация, г. Москва, ул. Трубецкая, д. 8, стр. 2

Представлены основные патогенетические аспекты розацеа, дана классификация и клинические проявления различных фрорм дерматоза. Указана сложность и противоречивость патогенетических фракторов, неоднозначная оценка их значимости в различных научных трудах. Определены основные триггеры возникновения и обострения дерматоза, которые необходимо учитывать при терапии для достижения стойкой, длительной ремиссии. В статье представлены первые результаты изучения эфффективности разработанной авторами комбинированной наружной терапии торпидных фрорм розацеа легкой и средней степени тяжести с применением 1 \% крема ивермектина и 0,03 \% мази такролимуса. Показана более высокая эфорективность предложенной комбинации по сравнению с монотерапией ивермектином и классической терапией розацеа кремом метронидазола и кремом азелаиновой кислоты; отмечено отсутствие побочных эфффектов и повышение приверженности больных среднетяжелых фрорм розацеа к комбинированной наружной терапии.

Ключевые слова: розацеа, наружная терапия, ивермектин, такролимус

Конфрликт интересов: авторы заявляют об отсутствии потенциального конфликта интересов, требующего раскрытия в данной статье.

Для цитирования: Смирнова Е. А., Олисова О. Ю., Кочергин Н. Г. Новая комбинированная наружная терапия торпидных фрорм розацеа. Вестник дерматологии и венерологии. 2018;94(4):21-29. https://doi.org/10.25208/0042-4609-2018-94-4-21-29 


\section{New combined topical therapy for refractory rosacea}

Elena A. Smirnova*, Olga Yu. Olisova, Nikolay G. Kochergin

I. M. Sechenov First Moscow State Medical University (Sechenov University)

of the Ministry of Health of the Russian Federation

Trubetskaya str., 8, building 2, Moscow, 119991, Russian Federation

The main pathogenetic aspects of rosacea, various classifications of dermatosis and the modern clinical classification are presented. The symptoms of different forms of rosacea are described. Contradictory of modern scientific concepts of different researchers, approaches to etiology, pathogenesis and treatment has been noted. The main triggers for the manifestation of rosacea, which should be taken into account to achieve the maximum effect in the treatment of the disease, are indicated. The first domestic positive experience of authors with $1 \%$ ivermectin cream and $0.03 \%$ tacrolimus ointment is presented. The high efficacy and very good tolerability of this combination, compared to monotherapy of $1 \%$ ivermectin cream and traditional therapy of metronidazole cream and azelaic acid gel as well as the absence of any side effects in patients with moderate to severe rosacea are shown.

Keywords: rosacea, topical therapy, ivermectin, tacrolimus

Conflict of interest: the authors state that there is no potential conflict of interest requiring disclosure in this article.

For citation: Smirnova E. A., Olisova O. Yu., Kochergin N. G. New combined topical therapy for refractory rosacea. Vestnik Dermatologii i Venerologii. 2018;94(4):21-29. https://doi.org/10.25208/0042-4609-2018-94-4-21-29 
Розацеа (син.: розовые угри, красные угри, acne rosacea, guttarosacea, cuperose, teleangiectasiasis faciei) относится к распространенным, хроническим воспалительным дерматозам мультифакторной природы, встречается повсеместно, характеризуется поражением центральной части лица в виде эритемы и папуло-пустулезных элементов.

Розацеа чаще встречается у светлокожих людей (I, II, реже III фототипа по Фицпатрику) [1] и преимущественно у женщин в возрасте 30-50 лет, однако самой тяжелой его формой - ринофимой - страдают почти исключительно мужчины [2].

Эпидемиологические исследования показывают распространенность розацеа в США и Европе в пределах 2,4-22 \%. В 2015 г. были получены данные по Германии и России в исследовании RISE (Rosacea International Study on Epidemiology), оценивающие популяционную частоту розацеа в Германии на уровне 12,3 \%, в России - 5,0\%. Также в этом исследовании отражены данные о повышенной чувствительности кожи к внешним фракторам у 83 \% пациентов с розацеа [3].

Проявления розацеа затрагивают исключительно лицо, что сразу бросается в глаза окружающим и ведет к социальной дезадаптации пациентов. Многие из них «уходят в болезнь», замыкаются в себе, страдают от депрессии, ограничивают общественную жизнь, а некоторые вынуждены бросать работу. Это нередко приводит к возникновению «нозогении» - психическое и невротическое расстройство, при котором состояние кожи лица выступает в роли психотравмирующего фактора. K этим негативным факторам прибавляется нередко встречающаяся устойчивость розацеа к терапии, недоверие пациента к врачу, что замыкает «порочный круг» течения заболевания.

Розацеа является сложным, малопредсказуемым, зачастую торпидным к лечению заболеванием, развитие которого определяется совокупностью генетической предрасположенности и фенотипических (триггерных) фракторов; при этом генетическая составляющая касается сосудистого компонента (ангионевроз) и иммунного реагирования; а основным негативным фрактором считается повышение содержания антимикробных пептидов - кателицидинов, что запускает воспалительную реакцию с участием нейтрофилов, Т-клеток и дендроцитов [4]. Фенотипическая составляющая напрямую зависит от генетической, то есть возникновение клинических симптомов дерматоза в ответ на воздействие обычных факторов, таких как повышенная температура, ультрафиолетовое излучение, и т. д., при наличии предрасположенности к розацеа [3].

$\mathrm{He}$ все патогенетические механизмы развития заболевания ясны до конца, однако подавляющее большинство ученых солидарны в том, что в основе дерматоза лежит повышенная реактивность сосудов кожи лица $[5,6]$. Доказано, что кровоток при розацеа выше по сравнению с нормальными показателями, при этом отмечается перманентное расширение сосудов поверхностной сети кожи, а диаметр сосудов больше диаметра сосудов по сравнению с нормальной кожей [7].

В некоторых исследованиях была изучена роль фактора роста сосудистого эндотелия (vascular endothelial growth factor - VEGF) в патогенезе розацеа, который вырабатывается кератиноцитами и который может активироваться как эндогенными, так и экзогенными триггерами. Показано, что его экспрессия в коже больных розацеа увеличивается от 55,6 до 88,9 \% по сравнению со здоровой кожей [8]. VEGF вызывает расширение сосудов, увеличивает их проницаемость, что ведет к стойкому приливу крови к коже лица; при этом показана взаимосвязь между повышением уровня VEGF и длительностью течения заболевания [9].

Остальные факторы, провоцирующие прилив крови к лицу, условно делятся на две основные группы: эндогенные и экзогенные.

Эндогенные факторы включают эндокринные, психовегетативные, иммунные (наличие антител к лимфоцитам, коллагену типа IV, циркулирующие иммунные комплексы, а также достоверное увеличение количества CD3 и CD4 Т-лимфоцитов на фроне уменьшения количества CD8 Т-лимфоцитов, что свидетельствует о развитии аутоиммунной реакции), заболевания пищеварительного тракта, связанные с инфицированием H. pilori; наличие микроорганизмов, в частности Demodex folliculorum (хотя он присутствует не у всех пациентов: частота его обнаружения колеблется от 40 до 95 \%); активация каллекреин-кининовой системы с увеличением продукции брадикинина.

Экзогенные фракторы подразумевают фризические воздействия (инсоляция, сильный ветер, перепады температуры, ионизирующая радиация), активные фризические упражнения, раздражающие косметологические процедуры, длительное местное применение глюкокортикостероидных препаратов, употребление раздражающей и горячей пищи, алкоголя [10, 11].

Существует несколько разных классификаций розацеа, основанных на клинических проявлениях заболевания. Исключение составляет классификация по МКБ 10 (розацеа, ринофима, другой вид розацеа, розацеа неуточненного вида), которая является статистической классификацией.

Существует клиническая классификация по стадиям заболевания:

- продромальный период: приливы;

- стадия 1: стойкая эритема, телеангиэктазии;

- стадия 2: стойкая эритема, телеангиэктазии, папулы, мелкие пустулы;

- стадия 3: стойкая насыщенная эритема, густая сеть телеангиэктазий, папулы, пустулы, узлы; иногда обширные инфильтраты в центральной части лица [11].

По современным представлениям, наиболее приемлемой представляется классификация по разновидностям дерматоза, предусматривающая четыре подтипа (варианта, формы):

- эритематозно-телеангиэктатический;

- папуло-пустулезный;

- фиматозный;

- офтальмологический.

По мнению экспертов Американского национального общества розацеа [12], классической стадийности прогрессирования заболевания не существует и различные варианты могут наблюдаться у одного и того же пациента. Диагноз розацеа строится на основании первичных и вторичных признаков (не менее двух первичных и двух вторичных) [12].

Первичные:

— приливы (преходящая эритема);

- стойкая эритема; 
- папулы и пустулы;

- телеангиэктазии.

Вторичные:

- жжение или покалывание;

- папулы/пустулы, сливающиеся в бляшки;

- сухость;

- отек;

- глазные проявления;

- фиматозные изменения.

Лечению розацеа посвящено множество руководств, монографий, статей. С одной стороны, существуют так называемые «стандарты лечения розацеа», содержащие лишь ограниченный набор лекарственных средств для лечения больных розацеа, и, с другой стороны, клинические рекомендации (национальные, международные), которые описывают широкий спектр терапевтических подходов, позволяющий практическим врачам делать более индивидуальный выбор для каждого отдельного больного.

Российские клинические рекомендации [13] предусматривают при лечении розацеа:

1. Системные препараты:

- антибиотики (доксициклин, эритромицин, кларитромицин);

- препараты группы 5-нитроимидазолов (метронидазол, орнидазол);

- ретиноиды (изотретиноин);

- ангиостабилизирующие препараты (алкалоиды белладонны + френобарбитал, эрготамин или ксантинола никотинат).

2. Местные препараты:

- метронидазол;

- азелаиновая кислота;

- антибиотики (клиндамицин);

- бензоила пероксид;

- топические ретиноиды;

- топические ингибиторы кальциневрина (пимекролимус и такролимус).

Международные рекомендации $[14,15]$ предлагают использовать:

1. Системные препараты:

- антибиотики (тетрациклины);

- антимикробные препараты (метронидазол);

- ретиноиды (изотретиноин).

2. Местные препараты:

- азелаиновую кислоту;

- метронидазол;

- $10 \%$ сульфрацетамид натрия с 5 \% серой;

- ивермектин;

- бримонидина тартрат.

Хотя в арсенале врачей есть много средств из различных групп для лечения больных розацеа, нередко встречаются случаи длительного, упорного течения дерматоза, и лечение у таких пациентов остается малоэффективным. При этом, испробовав «весь список» и не получив ожидаемого эффректа, пациенты бросают лечение и погружаются в депрессию. Для этих (и многих других случаев) актуальным становится необходимость разработки новых препаратов и схем лечения для достижения клинического эффекта в таких упорных случаях.

Примером может служить крем ивермектина $1 \%$ - новый препарат для лечения розацеа, зарегистрированный в РФ в 2016 г., который в наших первых исследованиях подтвердил свою достаточно высокую клиническую эфффективность [16]

Крем ивермектина 1 \% является принципиально новым лекарственным средством, имеющим двойной механизм действия: противопаразитарный и противовоспалительный. Ивермектин относится к полусинтетическим эндектоцидам из группы макроциклических лактонов, продуцируемых бактерией Streptomyces avermitili. Ранее его применяли внутрь для лечения различных эндопаразитарных инвазий, а также наружно для лечения экзопаразитических инвазий. Механизм действия заключается в блокаде специфических каналов, участвующих в передаче сигналов в нервных синапсах беспозвоночных, что ведет к их параличу и гибели (например, черви, клещи, вши, которые могут паразитировать на млекопитающих, включая людей). Применение ивермектина является эфффективным при т. н. демодекозе. Повышенное количество Demodex folliculorum встречается в коже лица больных розацеа по сравнению с кожей здоровых людей. Поскольку сообщалось о противовоспалительных свойствах ивермектина, терапевтическая активность препарата может быть связана с этими эфффектами, так как Demodex folliculorum присутствует не во всех случаях розацеа [16].

Противовоспалительное действие ивермектина заключается в подавлении клеточного и гуморального иммунного ответа, уменьшении фагоцитоза нейтрофилов, хемотаксиса и продукции оксидантов фагоцитами; он регулирует синтез фактора некроза опухолей-а, интерлейкина-1 $\beta$ и интерлейкина-10 при липополисахарид-индуцированном воспалении в исследованиях in vitro [3].

В 2011-2013 гг. в США и Канаде были проведены двойные слепые плацебо-контролируемые исследования [17], которые показали высокую эфффективность 1 \% крема ивермектина по сравнению с плацебо кремом при применении один раз в сутки у больных умеренной и тяжелой папуло-пустулезной розацеа $(n=1371)$. При этом в обоих исследованиях доля пациентов, достигшая успеха в лечении, который оценивался как полный или почти полный регресс симптомов (по IGA), была выше в группах $1 \%$ крема ивермектина, чем в группах плацебо: 38,4 и 40,1%; 11,6 и 18,8 \% соответственно. Высокая эффективность препарата сочеталась с незначительной частотой местных реакций (зуд, жжение), отсутствием серьезных побочных эфффектов.

В целях создания комбинированных, расширяющих возможности применения ивермектина методов наружной терапии упорных форм розацеа нами была разработана и запатентована (решение о выдаче патента на изобретение № 2017104879/15(008776) от 21.12.2017) новая комбинация применения двух наружных препаратов - крема ивермектина $1 \%$ и мази такролимуса 0,03 \% для лечения упорных случаев, преимущественно эритематозно-папулезной розацеа, позволяющая, на наш взгляд, сократить сроки достижения клинического эфффекта и удлинить возникшую ремиссию.

Как известно, такролимус - нестероидный противовоспалительный препарат, относящийся к группе природных макролидов и обладающий иммуносупрессивным действием, подавляет активацию Т-лимфоцитов, снижает выработку интерлейкинов, фактора некроза опухоли-а, уменьшает экспрессию рецепторов 
$\lg$ н на антиген-презентирующих клетках, предупреждает дегрануляцию тучных клеток и базофрилов [18].

Мазь такролимуса зарегистрирована в РФ как средство для лечения атопического дерматита, однако, согласно российским клиническим рекомендациям, может применяться и в терапии розацеа.

Преимуществами комбинации 1 \% крема ивермектина и 0,03 \% мази такролимуса перед монотерапией ивермектином, на наш взгляд, являются: фректа;

- потенцирование противовоспалительного эф-

- достижение и удлинение ремиссии, контроль и профилактика обострений;

- применение 1 раз в день (для каждого препарата), что повышает приверженность больных к терапии.

Исходя из вышесказанного, целью настоящего пилотного исследования явилась оценка эфффективности и безопасности комбинированного применения $1 \%$ крема ивермектина и 0,03 \% мази такролимуса по сравнению с классической терапией у больных упорной эритематозно-папулезной розацеа легкой и средней степени тяжести.

Под нашим наблюдением находились 75 пациенток в возрасте от 30 до 50 лет с установленным диагнозом «эритематозно-папулезная розацеа легкой и средней степени тяжести". Давность заболевания от

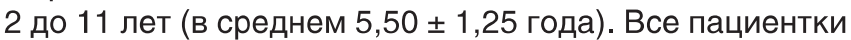
ранее получали лечение как наружными препаратами (метронидазол, адапален, бензоила пероксид, фузидовая кислота, и др.), так и системными препаратами (ретиноиды, антибиотики тетрациклиновой группы, метронидазол), однако лечение было малоэффективным. Помимо того, некоторые пациентки, совместно с основным лечением, принимали препараты из других групп: желудочно-кишечные средства, антигистаминные, седативные препараты.

Оценка выраженности клинических проявлений заболевания до и через 8 недель лечения основывалась на международных критериях IGA (investigator's global assessment - общая исследовательская оценка, табл. 1).

Тяжесть заболевания оценивалась по выраженности эритемы и количеству воспалительных высыпаний (папул/пустул) на каждом из пяти отделов лица: лоб, подбородок, нос, правая щека, левая щека. Клинические проявления заболевания у пациенток с легкой степенью тяжести сводились к умеренной эритеме без

Таблица 1. Оценка выраженности клинических проявлений розацеа по IGA Table 1. Evaluation of the severity of the clinical manifestations of rosacea according to IGA

\begin{tabular}{ccc}
\hline $\begin{array}{c}\text { Степень } \\
\text { выраженности }\end{array}$ & Баллы & Клиническая картина \\
\hline Отсутствует & 0 & $\begin{array}{c}\text { Воспалительные высыпания и эритема } \\
\text { отсутствуют }\end{array}$ \\
\hline $\begin{array}{c}\text { Почти } \\
\text { отсутствует }\end{array}$ & 1 & $\begin{array}{c}\text { Единичные мелкие папулы/пустулы, } \\
\text { очень легкая эритема }\end{array}$ \\
\hline Легкая & 2 & Несколько мелких папул/пустул, легкая \\
эритема
\end{tabular}

четких границ, занимающей $1 \frac{1}{3}-1 / 2$ кожи щек с единичными телеангиэктазиями и папулами; у пациенток со средней степенью тяжести эритема была более яркой и занимала всю поверхность кожи щек с умеренным количеством телеангиэктазий и папул.

Кроме того, оценивался дерматологический индекс качества жизни - ДИКЖ (от 0 до 30).

Оценка безопасности включала в себя регистрацию побочных эффектов и симптомов локальной переносимости препаратов (жжение/горение, сухость, зуд).

В результате скрининга из 90 первичных пациенток 15 больных не были включены в исследование в соответствии с критериями невключения:

- возраст до 18 лет;

- беременность, кормление грудью;

- тяжелая степень розацеа;

- сопутствующая вирусная, бактериальная и грибковая патология на коже лица;

- в анамнезе - длительное лечение местными стероидными средствами.

Критерии исключения из исследования:

— аллергические реакции на изучаемые препараты;

- беременность;

- отказ пациента от дальнейшего участия в исследовании.

Исследование было рандомизированным, проводилось в 3 параллельных группах. В первой группе (25 человек) пациентки применяли комбинированную терапию двумя препаратами: 1 \% крем ивермектина (утром) и 0,03 \% мазь такролимуса (вечером). Во второй группе (25 человек) пациентки применяли монотерапию $1 \%$ кремом ивермектина - 1 раз в день (утром) и индиффрерентный питательный крем (детский крем) в качестве плацебо к такролимусу (вечером). Третья группа (25 человек) была на классической терапии розацеа: $1 \%$ крем метронидазола 1 раз в день (утром) и $20 \%$ крем азелаиновой кислоты 1 раз в день (вечером). Препараты наносили тонким слоем на каждую из 5 зон лица (лоб, щеки, нос, подбородок), избегая попадания на губы, слизистые оболочки, глаза. Какой-либо другой наружной или системной терапии в течение периода наблюдения больные не получали.

Параллельно с лечением всем пациенткам было рекомендовано избегать триггерных фракторов, способствующих усилению высыпаний: соблюдать щадящую диету; не находиться под воздействием прямых солнечных лучей, холодного ветра, тяжелой физической нагрузки; не посещать сауну, баню, солярий; избегать эмоционального напряжения; в солнечные дни применять фотозащитные средства на лицо.

\section{Результаты}

Все три группы пациенток в начале лечения были сходны по дерматологическим проявлениям розацеа: у большинства участниц исследования была диагностирована розацеа средней степени тяжести, при наличии (в среднем) 27-29 \pm 1,7 воспалительных элементов, с умеренной эритемой. ДИКЖ до лечения составлял 17-19 \pm 0,9 балла (в среднем), что означает серьезное влияние на качество жизни пациенток.

Количество пациенток, достигших результата «отсутствует» или «почти отсутствует» симптоматика дерматоза к 8-й неделе лечения в 1-й группе составило 89,5\%, во 2-й группе - 70,4 \%, в 3-й группе - 53,5 \%. Заметная 


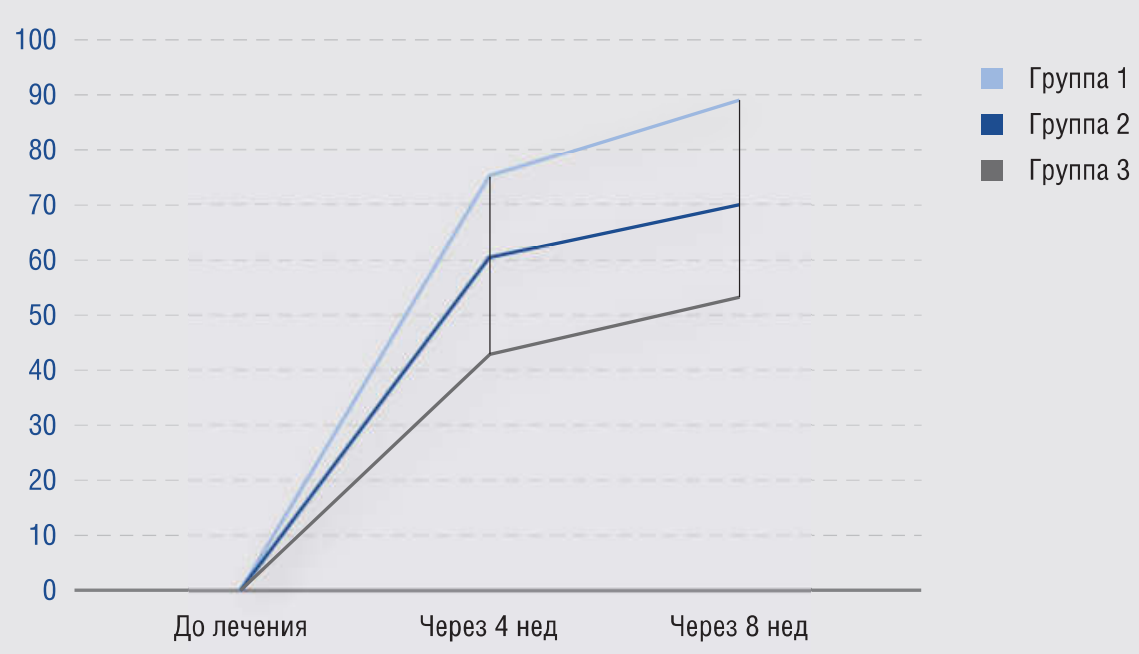

Pис. 1. Процент участниц с результатом «отсутствует» или «почти отсутствует» согласно IGA по группам Fig. 1. Percentage of participants with "absent" or "almost absent" result according to IGA by groups

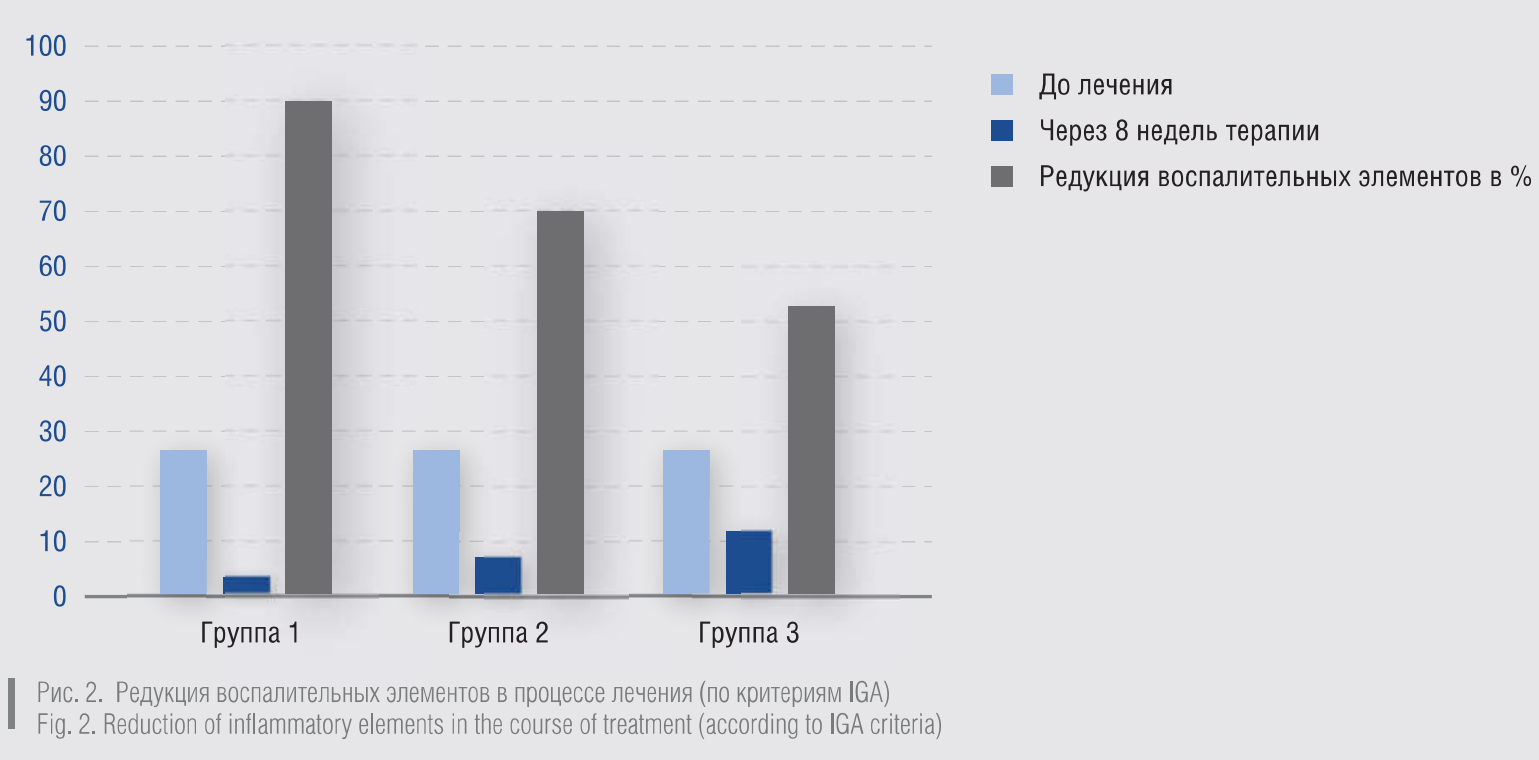

разница между группами наблюдалась к 4-й неделе лечения $(75,5 ; 60,7$ и 43,1 \% соответственно) (рис. 1$)$.

Количество воспалительных элементов уменьшилось к 8-й неделе лечения на 25,5 $\pm 1,5$ в 1-й группе, на 20,3 \pm 1,2 во 2-й группе, на 15,2 \pm 0,9 - в 3-й группе; что означает редукцию воспалительных элементов в 1-й группе - на 91,07 \%, во 2-й группе - на 72,5\%, в 3-й группе - на 54,28; $p<0,05$ (рис. 2).

ДИКЖ в первой группе после лечения составил 3 балла, во второй - 4, в третьей - 8 баллов, что означает минимальное (для первых двух групп) и умеренное (для третьей группы) воздействие на качество жизни пациенток.

Все пациентки переносили лечение очень хорошо, каких-либо побочных эффектов в данном исследовании не наблюдалось. Две пациентки отмечали, что 0,03 \% мазь такролимуса оставляет жирный блеск на лице; им было рекомендовано уменьшить количество нанесения лекарственного средства.

После окончания основного курса пациенткам 1-й группы было рекомендовано применять 0,03 \% мазь такролимуса в качестве поддерживающей терапии по схеме постепенного сокращения частоты смазывания: 2-3 раза в неделю - в течение первого месяца, 1-2 раза в неделю - в течение следующего месяца и далее вплоть до полной отмены препарата при отсутствии клинических симптомов розацеа.

Исследование по результатам наблюдения в отдаленные сроки продолжается.

Таким образом, комбинированная терапия эритематозно-папулезной розацеа $1 \%$ кремом ивермектина и 0,03 \% мазью такролимуса дает более быстрый и выраженный клинический эффект, чем монотерапия $1 \%$ кремом ивермектина. Классическая комбинированная терапия розацеа 1 \% кремом метронидазола и 20 \% кремом азелаиновой кислоты значительно отстает по эффективности от двух вышеперечисленных схем. По-видимому, наиболее выраженный клинический эффрект комбинированной терапии 1 \% кремом ивермектина и 0,03 \% мазью такролимуса напрямую связан с потенцированием противовоспалительного действия двух препаратов: количество пациенток, достигших результата «отсутствует» или «почти отсутствует» симптоматика дерматоза к 8-й неделе лечения в 1-й группе 
27 № 4,2018

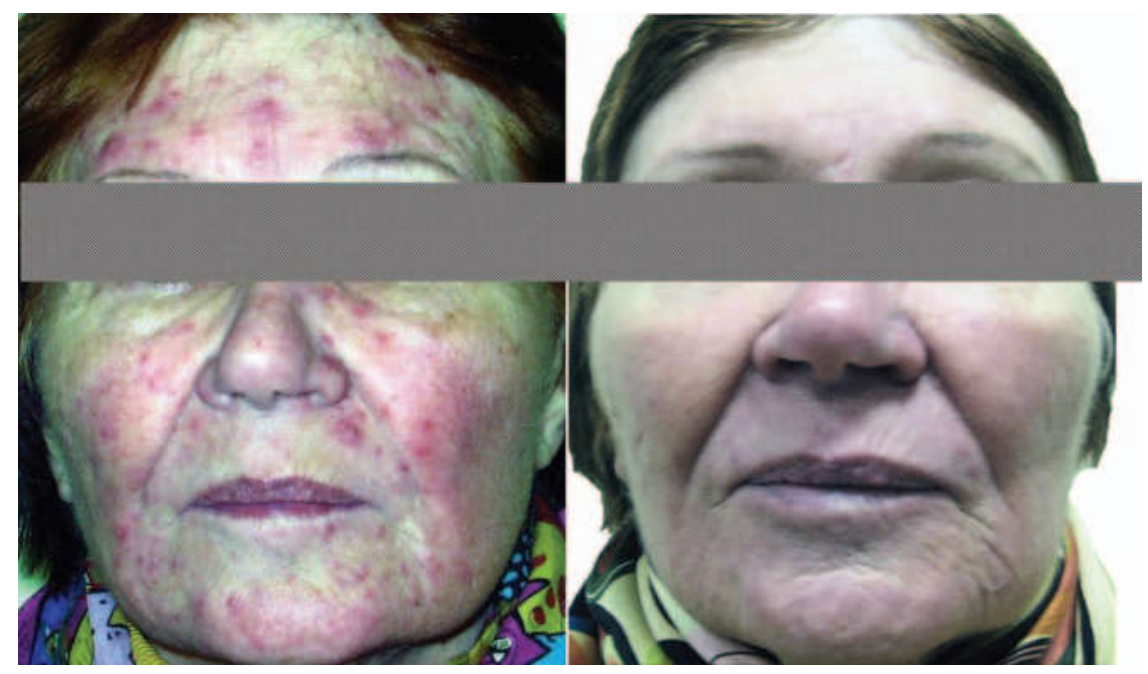

Рис. 3. Пациентка Б. Розацеа, эритематозно-папулезный подтип (единичные пустулы). Результаты комбинированной терапии 1 \% кремом ивермектина и 0,03 \% мазью такролимуса (до и через 8 недель от начала терапии)

Fig. 3. Patient B. Rosacea, erythematopapular subtype (single pustules). Results of combination therapy with $1 \%$ ivermectin cream and $0.03 \%$ tacrolimus ointment (before and after 8 weeks from the start of therapy)

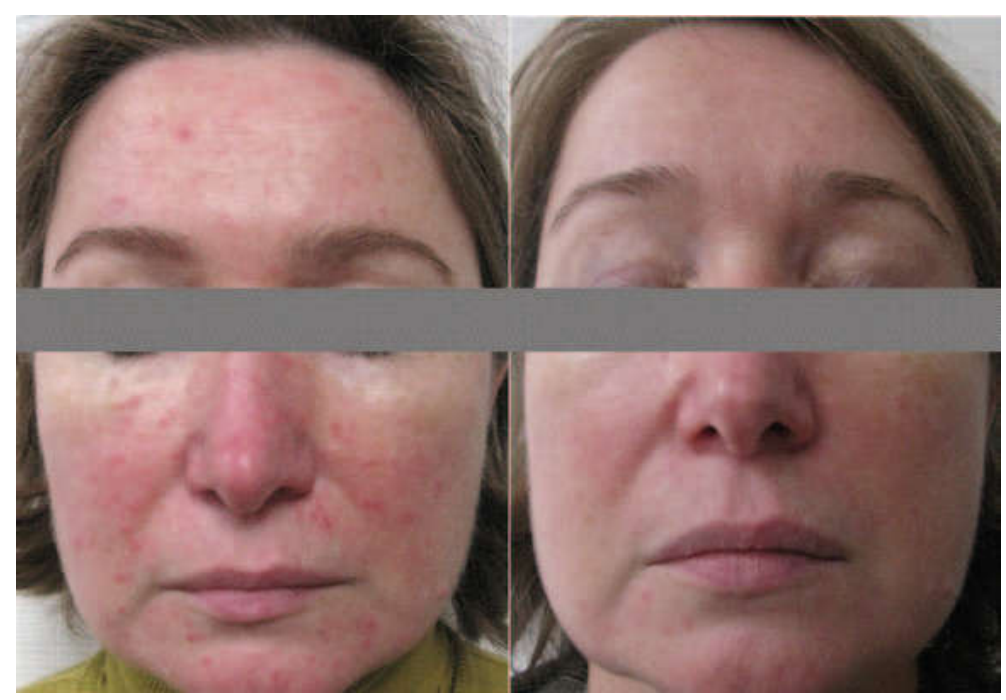

Рис. 4. Пациентка С. Розацеа, эритематозно-папулезный подтип. Результаты монотерапии 1 \% кремом ивермектина (до и через 8 недель от начала терапии) Fig. 4. Patient S. Rosacea, erythematopapular subtype. The results of monotherapy with $1 \%$ ivermectin cream (before and after 8 weeks from the start of therapy)



Рис. 5. Пациентка А. Розацеа, эритематозно-телеангиоэктатический подтип (единичные папулы). Результаты комбинированной терапии 1 \% кремом ивермектина и $0,03 \%$ мазью такролимуса (до и через 8 недель от начала терапии)

Fig. 5. Patient A. Rosacea, erythematotelangiectatic subtype (single papules). The results of combination therapy with $1 \%$ ivermectin cream and $0.03 \%$ tacrolimus ointment (before and after 8 weeks from the start of therapy) 
составило 89,5 \% (рис. 3, 5), во 2-й - 70,4 \% (рис. 4), а в 3-й - лишь 53,5\%. Наиболее значимые различия между группами наблюдались к 4 неделе лечения.

Полученные результаты проведенного исследования позволяют рекомендовать предложенную комбина- цию 1 \% крема ивермектина и 0,03 \% мази такролимуса в качестве одного из высокоэффрективных методов наружной терапии торпидных к стандартному лечению случаев среднетяжелых орорм эритематозно-папулезной розацеа.

\section{Литература/References}

1. Манн М. В., Берк Д. Р., Попкин Д. Л., Бейлисс С. Д. Справочник дерматолога. Практическое руководство. Пер. с англ. М.: Изд. Панфилова; БИНОМ, 2013. [Mann M. W., Berk D. R., Popkin D. L., Bayliss S. J. Handbook of Dermatology. A Practical Manual. Trans. from English. Moscow: Panfilov Publishing; BINOM, 2013. (In Russ.)]

2. Aziz N., Khachemoune A. A man with changes on nose. J Am Acad Dermatol. 2007:57(3):551-554. http://www.jaad.org/article/S01909622(07)00875-4/abstract

3. Круглова Л. С., Бакулев А. Л., Софринская Г. В. Применение ивермектина и бримонидина тартрата при различных подтипах розацеа. Учебное пособие. Москва: ФГБУ ДПО «Центральная государственная медицинская академия Управления делами Президента РФ», 2017. [Kruglova L. S., Bakulev A. L., Sofinskaya G. V. The use of ivermectin and brimonidine tartrate in various subtypes of rosacea. Textbook. Moscow: Central State Medical Academy of the Office of the President of the Russian Federation, 2017. (In Russ.)]

4. Олисова О. Ю., Кочергин Н. Г., Смирнова Е. А. Современная наружная терапия среднетяжелых форм розацеа. Российский журнал кожных и венерических болезней. 2016;19(6):328-334. [Olisova O. Yu., Kochergin N. G., Smirnova E. A. Modern external therapy of moderate rosacea. Russian Journal of Skin and Sexually Transmitted Diseases. 2016;19(6):328-334. (In Russ.)]

5. Dirschka T., Micali G., Papadopoulos L., Tan J., Layton A., Moore S. Perceptions on the psychological impact of facial erythema associated with rosacea: results of international survey. Dermatol Ther (Heidelb). 2015;5(2):117-127

6. Phillips T. J. An update on the safety and efficacy of topical retinoids. Cutis. 2005;75(2, Suppl):14-22.

7. Самцов А. В. Акне и акнесормные дерматозы. Монограсиия. M: ФAPMTEK; 2014. [Samtsov A. V. Acne and acneform dermatoses. Monograph. Moscow: PHARMTEK, 2014. (In Russ.)]

8. Кубанова А. А., Махакова Ю. Б. Розацеа: распространенность, патогенез, особенности клинических проявлений. Вестник дерматологии и венерологии. 2015;(3):36-45. [Kubanova A. A., Makhakova Yu. B. Rosacea: prevalence, pathogenesis, the features of clinical manifestations. Vestnik Dermatologii i Venerologii. 2015;(3):36-45. (In Russ.)]

9. Пинсон И. Я., Верхогляд И. В., Семочкин А. В. Современные представления об этиологии и патогенезе розацеа. Экспериментальная и клиническая дерматокосметология. 2012;5:21-24. [Pinson I. Ya., Verkhoglyad I. V., Semochkin A. V. Modern ideas about the etiology and pathogenesis of rosacea. Experimental and Clinical Dermatocosmetology. 2012:5:21-24. (In Russ.)]

10. Бутов Ю. С., Скрипкин Ю. К., Иванов О. Л. (ред.) Дерматовенерология. М.: ГЭОТАР-Медиа, 2013. [Butov Yu. S., Skripkin Yu. K.,
Ivanov O. L. (eds) Dermatovenereology. Moscow: GEOTAR-Media, 2013. (In Russ.)]

11. Ахтямов С. Н. Практическая дерматокосметология. Акне, рубцы постакне и акнесоормные дерматозы. Руководство для врачей. М.: Медицина, 2010. [Akhtyamov S. N. Practical dermatocosmetology. Acne, post-acne scars and acneform dermatoses. A guide for doctors. Moscow: Meditsina, 2010. (In Russ.)]

12. Wilkin J., Dahl M., Detmar M., Drake L., Feinstein A., Odom R., Powell F. Standard classification of rosacea: report of the National rosacea society expert committee on the classification and staging of rosacea. J Am Acad Dermatol. 2002;46:584-587.

13. Аравийская Е. Р., Самцов А. В. Федеральные клинические рекомендации по ведению больных розацеа. М., 2013. [Araviyskaya E. R., Samtsov A. V. Federal clinical guidelines for the management of rosacea patients. Moscow, 2013. (In Russ.)]

14. Вольф К., Голдсмит Л. А., Кац С. И., Джилкрест Б. А., Паллер Э. С., Лефффель Д. Дж. Дерматология Фицпатрика в клинической практике. Пер. с англ. М.: Изд. Панфилова; БИНОМ, 2012. Т. 1: 772774. [Wolff K., Goldsmith L., Katz S., Gilchrest B., Paller A.S., Leffell D. Fitzpatrick's dermatology in general medicine. Trans. from English. Moscow: Panfilov Publishing. BINOM, 2012. Vol. 1: 772-774. (In Russ.)]

15. Дел Россо Д. Розацеа кожи: патогенез, клинические проявления, современные рекомендации по тактике ведения пациентов. Вестник дерматологии и венерологии. 2016;2:21-31. [Del Rosso D. Skin Rosacea: pathogenesis, clinical manifestations, current guidelines on patient management tactics. Vestnik Dermatologii i Venerologii. 2016;2:21-31. (In Russ.)]

16. Олисова О. Ю., Кочергин Н. Г., Смирнова Е. А. Инновации в наружной терапии розацеа. Российский журнал кожных и венерических болезней. 2017;20(5):270-274. [Olisova 0. Yu., Kochergin N. G., Smirnova E. A. Innovations in rosacea external therapy. Russian Journal of Skin and Sexually Transmitted Diseases. 2017;20(5):270-274. (In Russ.)]

17. Stein L., Kircik L., Fowler J., Tan J., Draelos Z., Fleischer A. et al. Efficacy and safety of ivermectin $1 \%$ cream in treatment of papulopustular rosacea: results of two randomized, double-blind, vehicle-controlled pivotal studies. J Drugs Dermatol. 2014;13(3):316-323.

18. Олисова 0. Ю., Кочергин Н. Г., Мураховская Е. К., Кескин Г. М., Олисов А. О., Давидович М. и др. Такролимус в терапии различных дерматозов. Российский журнал кожных и венерических болезней. 2013;16(5):57-61. [0lisova 0. Yu., Kochergin N. G., Murakhovskaya E. K., Keskin G. M., Olisov A. O., Davidovich M. et al. Tacrolimus in the treatment of various dermatoses. Russian Journal of Skin and Sexually Transmitted Diseases. 2013;16(5):57-61. (In Russ.)] 


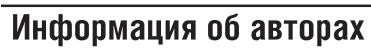

Елена Анатольевна Смирнова* - аспирант кафедры кожных и венерических болезней лечебного фракультета Первого Московского государственного медицинского университета им. И. М. Сеченова (Сеченовского университета) Министерства здравоохранения Российской Федерации; e-mail: doctor.e.smirnova@gmail.com

Ольга Юрьевна Олисова - д.м.Н., профессор, заведующая кафедрой кожных и венерических болезней лечебного факультета Первого Московского государственного медицинского университета им. И. М. Сеченова (Сеченовского университета) Министерства здравоохранения Российской Федерации

Николай Георгиевич Кочергин - д.м.Н., профессор кафедры кожных и венерических болезней лечебного факультета Первого Московского государственного медицинского университета им. И. М. Сеченова (Сеченовского университета) Министерства здравоохранения Российской Федерации

\section{Information about the authors}

Elena A. Smirnova* - Postgraduate student, Department of Dermatology and Venereology, Faculty of Medicine, I. M. Sechenov First Moscow State Medical University (Sechenov University) of the Ministry of Health of the Russian Federation; e-mail: doctor.e.smirnova@gmail.com

Olga Yu. Olisova - Dr. Sci. (Med.), Prof., Departmental Head, Department of Dermatology and Venereology, Faculty of Medicine, I. M. Sechenov First Moscow State Medical University (Sechenov University) of the Ministry of Health of the Russian Federation

Nikolay G. Kochergin — Dr. Sci. (Med.), Prof., Department of Dermatology and Venereology, Faculty of Medicine, I. M. Sechenov First Moscow State Medical University (Sechenov University) of the Ministry of Health of the Russian Federation 